\title{
ECG QT Correction Model Data Supplemental Qualifiers Dataset
}

National Cancer Institute

\section{Source}

National Cancer Institute. ECG QT Correction Model Data Supplemental Qualifiers

Dataset. NCI Thesaurus. Code C147241.

A dataset containing supplemental information, specifically non-standard variables, to parent records in the ECG QT correction model data domain. 